\title{
Effects of sexual dimorphism on pollinator behaviour in a
}

\section{dioecious species}

3

Authors: L. Moquet ${ }^{1,2}$, A-L Jacquemart ${ }^{3}$, M. Dufay ${ }^{1,4, \#, *}$ and I. De Cauwer ${ }^{1, \#}$

Author affiliations: 1. Univ. Lille, CNRS, UMR 8198 - Evo-Eco-Paleo, F-59000 Lille, France

4. Present Address: CEFE, Univ Montpellier, CNRS, EPHE, IRD, Montpellier, France

\# These authors share senior authorship

* For correspondence. Email:mathilde.dufay@umontpellier.fr 


\section{Summary}

Floral traits often display sexual dimorphism in insect-pollinated dioecious plant species, with male individuals typically being showier than females. While this strategy is theorized to be optimal when pollinators are abundant, it might represent a risk when they become scarce, because the disproportionately high number of visits on the most attractive sex, males, might preclude efficient pollen transfer from males to females. Here, the effect of sexual dimorphism on pollination efficiency was assessed in experimental arrays of dioecious Silene dioica that were exposed to one frequent visitor of the species, Bombus terrestris, and that differed in the magnitude of sexual dimorphism for either flower number or flower size. While flower size dimorphism did not impact pollination efficiency, we found that flower number dimorphism negatively affected the number of visits on female plants, on female flowers and on the number of female flowers visited after a male flower. However, flower number dimorphism had no effect on the number of pollen grains deposited per stigma, presumably because the decrease in the number of visits to female flowers was compensated by a higher number of pollen grains deposited per visit.

Key words: Dioecy, floral trait sexual dimorphism, pollination, visitation sequence, pollen transfer, Silene dioica 


\section{Introduction}

One common feature in plants with separate sexes is sexual dimorphism, both in terms of vegetative and reproductive traits (reviewed in Barrett and Hough 2013). In insect-pollinated dioecious species, male plants often display more conspicuous floral phenotypes than females, at least in temperate species, with males typically producing larger floral displays and/or larger flowers (Guitián 1995, Delph et al. 1996, Pailler et al. 1998, Eckhart 1999, Costich and Meagher 2001, Ramsey and Vaughton 2001, Kriebel 2014, Matsuhisa and Ushimaru 2015, Cuevas et al. 2017). One common explanation for this pattern is sexual selection: if male's reproductive success is more limited by mate acquisition than female's reproductive success (as predicted by Bateman principles, Bateman 1948), any trait involved in pollinator attraction should be under stronger selection in males than in females (Delph and Ashman 2006, Moore and Pannell 2011).

Pollinators have been shown to preferentially visit male plants in several dioecious species (e.g. Ågren et al. 1986, Carlsson-Granér et al. 1998). This preference can be driven by the difference between males and females in terms of flower number or size (e.g. Vaughton and Ramsey 1998, Bond and Maze 1999, Pickering 2001) and/or associated with other male specificities, such as the occurrence of stamen and pollen (Lunau 2000, Nicholls and Hempel de Ibarra 2017). One potential consequence of unbalanced visitation rates between sexes is that females might, on average, not receive enough visits for optimal pollination. When female's reproductive success is pollen limited, the strength of selection on attractive floral traits in females is expected to increase (Sletvold and Ågren 2016, Caruso et al. 2019), which could potentially result in a decrease in the magnitude of sexual dimorphism. However, an abrupt decrease in pollinator abundance could have deleterious demographic effects well before any evolutionary response could take place. Accordingly, the modelling study by Vamosi and Otto (2002) predicts that pollinator preference towards one sex, in this case males, could lead to population extinction when pollinators are scarce and when plants display a high degree of sexual dimorphism.

To date, only a few experimental studies have examined the effect of sexual dimorphism on pollinator behaviour at the plant population level. By manipulating the distribution of floral size between males and females in experimental arrays of the dioecious Sagittaria latifolia, Glaettli and Barrett (2008) 
showed that the proportion of pollinator visits on males increased with the magnitude of floral size sexual dimorphism. This pattern resulted from an increase in the number of visits on males, with no change in the number of visits on females. Based on their results, the authors argued that males might benefit from showier flowers in terms of pollen export, whereas increased sexual dimorphism should not impact female reproductive success in this system. In a similar study, Vaughton and Ramsey (1998) manipulated the occurrence of flower number dimorphism in Wurmbea dioica and found that pollinators preferred males even when flower number was the same in both sexes, possibly due to the larger flower sizes in males. However, since no pollen limitation was detected, this preference for males should not have incurred any demographic cost in the study population. As underlined by these two studies, the effect of sexual dimorphism on the number of visits received by females is not necessarily a good predictor of pollination efficiency. To test the hypothesis that the magnitude of sexual dimorphism negatively impacts pollination, one also needs to measure pollen transfer, which depends not only on the number of visits on females, but also on the quantity of pollen carried by insects, which might in turn depend on whether or not insects visited male flowers before reaching female flowers. Yet, the order of visits on male and female flowers by pollinators has rarely been investigated (but see Tsuji et al. 2020), and the consequences of sexual dimorphism on the ability of pollinators to efficiently transfer pollen from male to female flowers remains unclear and largely untested.

In the current study, we examined the effect of sexual dimorphism on pollinator behaviour and pollen transfer in Silene dioica. This species shows sexual dimorphism for a variety of traits, including floral size and floral number, with males producing markedly larger and more abundant flowers than females (Kay et al. 1984, Moquet et al. 2020). In this species, males have been shown to attract more pollinators than females, possibly as a consequence of their showier displays (Kay et al. 1984, CarlssonGranér et al. 1998 ). Here, we independently manipulated the magnitude of sexual dimorphism in flower number and flower size in experimental populations and quantified the effect of this variation on the visitation patterns of Bombus terrestris, a frequent visitor of the study species in natura (Kay et al. 1984). Because the negative effects of sexual dimorphism on pollination efficiency are expected to occur when pollinators are scarce (Vamosi and Otto 2002), the number of pollinator visits was fixed and 

where males and females showed no sexual dimorphism with arrays in which sex dimorphism occurred for only one of the two traits, we were able to disentangle the effects of flower number and flower size on visitation patterns. We measured the number of visits on male and female plants and flowers, the visiting sequences (order of visits on male and female flowers), and the pollen transfer to stigmas. Our prediction is that pollination efficiency will be lower in sexually dimorphic experimental populations

94 than in populations where there are no differences between males and females in terms of floral visual signalling. 


\section{Material and methods}

\section{Experimental plants and bumblebee species}

Silene dioica is a common perennial herb of north-western Europe, flowering from April to June (Kay et al. 1984). This species has a generalist insect-pollination system, with Bombus species and syrphids as most common visitors (Baker 1947). Female flowers have five stigmas and male flowers ten stamens. Males typically carry showier displays than females: on average, they produce over ten times more flowers over the course of the flowering season, with corollas that are $20 \%$ wider than in females (Moquet et al. 2020). Both male and female flowers secrete nectar at the base of the corolla (Vogel 1998, Comba et al. 1999), with male flowers producing less abundant but more concentrated nectar than female flowers (Kay et al. 1984, Comba et al. 1999). We used the same experimental material as in Moquet et al. (2020): plants originated from seeds collected in July 2015 and 2016 in eight natural populations in northern France. Seeds were sown in autumn the same year they were harvested. Prior to the experiment, which was carried out in spring 2017, plants were vernalized for 10 weeks at $6{ }^{\circ} \mathrm{C}$ (Lille University, France) and placed in an experimental garden until the flowering season (catholic University of Leuven, Belgium).

Bombus terrestris is a frequent visitor of S. dioica (Baker 1947, Kay et al. 1984, Goulson and Jerrim 1997). We used colonies of B. terrestris from BioBest Biological Systems (Westerlo, Belgium) in which we removed access to the factory-supplied nectar reservoir during the experiment to encourage foraging. Pollen was delivered ad-libidum directly to the nests.

\section{Experimental design}

To test whether the occurrence of sexual dimorphism in flower number and/or size impacted visitation rates, pollinator behavior, and pollen transfer from male flowers to female stigmas, we ran experiments in an indoor flight arena $(2.80 \times 2.20 \times 2.00 \mathrm{~m}, \mathrm{~L}$ x W x H) in May and June 2017. For each experimental session, we selected ten plants, five females and five males, according to their characteristics in terms of corolla diameter and flower number on the observation day. We counted the number of flowers and measured corolla diameter on five randomly selected flowers with a digital calliper precise to $0.01 \mathrm{~mm}$. 
When less than five flowers were available, all the flowers were measured. The 24 observation sessions were distributed across three treatments (Figure 1):

(i) male and female corolla of equivalent size, more male flowers than female flowers (flower number dimorphism, $\mathrm{n}=8$ )

(ii) male corolla larger than female corolla, an equal number of flowers (flower size dimorphism, $\mathrm{n}=8$ sessions), and

(iii) male and female corolla of equivalent size, an equal number of flowers (no dimorphism, $\mathrm{n}=8$ sessions).

Within the flight arena, plants were arranged in four rows (row 1 and 3: three plants, row 2 and 4: two plants). Within and between rows, neighboring plants were separated by exactly $40 \mathrm{~cm}$. Male and female plant positions were randomly arranged each session.

The day before the experiment, plants were placed in a greenhouse to exclude nectar-feeding insects and allow nectar replenishment. Flower buds were marked with a water-based marker pen in order to identify the virgin flowers that were used to estimate pollen loads after each observation session.

\section{Training phase}

Three different hives were used, alternating hive $\times$ treatment combinations. Before the experiment, bumblebees were allowed to familiarize with the flight arenas and with reward collection. During this training phase, one hive was open, and bumblebees could move freely. Bumblebees were trained on six plants ( 3 males, 3 females) randomly arranged in the flight arena. In order to limit the establishment of a plant-sex preference, plants were selected to have similar characteristics (plant size, flower numbers, and corolla size). We ran five training sessions of $30 \mathrm{~min}$ for each colony before the observation sessions, then one 30 min training session every two weeks.

\section{Observation protocol}

Each observation session, five individual bumblebees were released one by one, in the flight arena. One observer, posted behind a net, noted the bumblebees visiting sequences. Any occurrence of a bumblebees probing a flower was recorded as a visit. Bumblebees were captured and marked after they 
visited ten flowers. In the rare cases where bumblebees did visit fewer than ten flowers and stopped foraging for more than 10 minutes, the trial was stopped and a sixth trial was performed. Each session consisted of exactly 50 visits (five bumblebees $\times$ ten visits) in the flight cage. Because the maximum number of flowers per session was 50 for all treatments, all flowers had a chance to be visited at least once. Some flowers were visited more than once, thus, the amount of reward of an individual flower could decline during each session. This experiment thus mimics common situations in which nectar secretion rates are weak in comparison to visitation rates (Real 1981, Ashworth and Galetto 2002, Barp et al. 2011).

\section{Pollen transfer}

One day after the experiment, we individually collected styles of one or two marked flowers per female plant in order to analyse the quantity of pollen deposited onto the stigmas. Styles were kept in FAA (ethanol 70\%: formaldehyde 35\%: acetic acid; 8:1:1) until analysis. Before observation, styles were rinsed with demineralised water for one hour, soaked in a sodium hydroxide (4M) for three hours, and again rinsed in water for approximatively one hour. Styles were then put on a microscope slide with a drop of aniline blue solution $\left(0.87 \mathrm{~g} \mathrm{KH}_{2} \mathrm{PO}_{4}, 0.1 \mathrm{~g}\right.$ of aniline blue, $50 \mathrm{ml}$ water $)$ and pollen grains were counted under a fluorescence microscope (excitation filter $420-440 \mathrm{~nm}$, emission filter $480 \mathrm{~nm}$, Nikon Eclipse).

\section{Statistical analysis}

Generalized linear mixed models (GLMM) were used to test for the effects of sexual dimorphism on 1) the distribution of visits between male and female plants during a session, 2) the characteristics of the visit sequence performed by each bumblebee and 3) the pollen transfer from male to female flowers. For all following analyses, the effects of "flower number dimorphism" and "flower size dimorphism" treatments were assessed separately using comparisons with the "no dimorphism" treatment. For each model, hive and observation session were primarily added as random factors and were removed when they had no influence on our models. All models were realised with the lme4 package in R version 4.0.2 (R Development Core Team 2008). 
Distribution of visits among male and female plants -- We tested whether plant sex, treatment and sex

$x$ treatment interaction had an influence on the number of bumblebee visits received by each plant. In these models, the individual was the unit of analysis $(n=80$ plants per treatment). Two response variables were considered: i) the total number of visits per plant and ii) an estimate of the number of visits per flower (number of visits on one plant divided by the number of open flowers on this plant) during one session. We used a negative binomial distribution for the first model and a Gaussian distribution for the second one.

Sequences of visits -- We tested for the effect of treatment on several characteristics of the visit sequence performed by each bumblebee. In these models, bumblebee foraging bouts were thus the unit of analysis. Only complete sequences (i.e. 10 flowers visited) were kept ( $n=34,36$ and 39 sequences for "flower number dimorphism", "flower size dimorphism" and "no dimorphism" treatments, respectively). The response variables were: (i) the number of visited females, (ii) the number of visited female flowers, (iii) the number of visited female flowers divided by the total number of female flowers available in the experimental plot, (iv) the number of female flowers visited after the insect had visited at least one male flower, which provides an estimate of the number of potentially pollinating visits, and (v) the sex of the first visited flower. Moreover, because there was no time for nectar replenishment between bumblebee trials, we added bumblebee flying order (from 1 to 5) as an explanatory variable in the model, as well as the treatment $\times$ order interaction. We used binomial distributions for models analyzing variable (v), gaussian for models analysing variable (iii) and Poisson distributions for the other variables.

Regarding the number of female flowers visited after at least one male flower, this variable should depend on both the number of female flowers in the sequence and the order of the visits. For each observed visit sequence, we thus simulated 1000 random sequences of 10 flowers and containing the same number of female flowers. We then measured the proportion of simulated sequences that had a lower number of visited females after at least one male compared to the observed sequence. When this proportion was lower than 0.05 , we considered the sequence to depart from expectations under random behaviour of the insect. 
bioRxiv preprint doi: https://doi.org/10.1101/2021.04 15.440026; this version posted April 15, 2021. The copyright holder for this preprint

(which was not certified by peer review) is the author/funder, who has granted bioRxiv a license to display the preprint in perpetuity. It is made available under aCC-BY 4.0 International license.

200 Pollen deposition -- To test whether floral sexual dimorphism affected pollination success, we analyzed

201 the effects of the treatment on the number of pollen grains deposited on collected stigmas. When more

202 than one stigma was collected, pollen quantity was averaged across stigmas $(n=40$ females for the

203 "flower number" treatment, $\mathrm{n}=36$ for the two other treatments). Because a low number of open flowers

204 on a given female potentially concentrates all deposited pollen grains on the same stigmas, we added

205 the number of open flowers as a co-variable and tested for the interaction between treatment and flower

206 number. We used a distribution of Poisson in these models. 


\section{Results}

Does sexual dimorphism affect the distribution of visits on male and female plants?

When comparing the number of visits received per plant between the "flower number dimorphism" and the "no dimorphism" treatment, we detected an effect of both plant sex $\left(\chi_{1}^{2}=9.604, P=0.002\right)$ and the interaction between plant sex and treatment $\left(\chi_{1}^{2}=39.593, P<0.001\right)$. In the sessions with no sexual dimorphism, female plants received slightly more visits than male plants, and this pattern was reversed when male plants carried more flowers (Fig. 2A). Only plant sex had a significant effect $\left(\chi_{1}^{2}=5.816, P\right.$ $=0.016)$ on the number of visits per flower, with higher visitation rates on females in both treatments (Fig. 2B).

Regarding the comparison between the "flower size dimorphism" and the "no dimorphism" treatments, although the number of visits per plant and per flower was similar in males and females when males produced larger flowers, the interaction between plant sex and treatment was not significant (Fig. 2C and 2D).

Does sexual dimorphism impact the characteristics of visitation sequences?

Bumblebee behavior was found to be statistically similar between the "flower size dimorphism" and the "no dimorphism" treatments for all tested variables. On the contrary, when comparing bumblebee behavior between the "flower number dimorphism" and the "no dimorphism" treatment, we found significant differences for several metrics (Fig. 3). Sexual dimorphism for flower number reduced the number of visited female plants $\left(\chi_{1}^{2}=11.271, P<0.001\right)$ and female flowers $\left(\chi_{1}^{2}=63.099, P<0.001\right)$, as well as the number of female flowers visited after a male flower $\left(\chi_{1}^{2}=26.551, P<0.001\right)$. The sex of the first visited flower was also affected $\left(\chi_{1}^{2}=10.016, P=0.002\right)$, with a first visit on a male flower in $74 \%$ of sequences in the "flower number dimorphism" treatment, against $36 \%$ of sequences in the "no dimorphism" treatment. Treatment did not affect the number of visited female flowers when corrected by the total number of female flowers available in the arena $\left(\chi_{1}^{2}=0.083, P=0.068\right)$. Bumblebee flying order and the order $\times$ treatment interaction did not impact any of the tested response variables $(P>0.05)$. 
232 The number of female flowers visited after at least one male flower was significantly lower than

233 expected under random behaviour in a fifth of the visitation sequences in the "no dimorphism" treatment

234 (8 of the 39 observed sequences). In these sequences, visits started by one or several female flower(s),

235 thus reducing the number of potentially pollinating visits: overall, in this treatment, 87 of the 230 visited

236 females' flowers were visited before any visit on a male flower, implying that $38 \%$ of visited female

237 flowers could not receive any pollen. Such deviations from random expectations were observed only

238 twice in the "flower size dimorphism" treatment, and never in the "flower number dimorphism"

239 treatment.

Effects of floral dimorphism on pollination success

241 Both in case of flower number and flower size dimorphism, treatment, number of flowers and the interaction between these two variables had no influence on the average number of pollen grains deposited on collected stigmas $(P>0.05$, Fig. 4). 


\section{Discussion}

While the effects of floral traits on pollinator attraction have been studied extensively (e.g. Conner and Rush 1996, Spaethe et al. 2001, Martin 2004, Hegland and Totland 2005, Ishii 2006), the response of pollinators to between sexes variation in floral phenotypes is less well understood, despite the fact that sexual dimorphism for floral traits is a common feature in insect-pollinated dioecious plants (e.g. Delph et al. 1996, Eckhart 1999). In S. dioica, as in many dioecious plant species, males are typically showier than females, with larger floral displays both in terms of flower number and flower size (Kay et al. 1984, Moquet et al. 2020), and flower visitors of Silene dioica have been shown to prefer male over female plants under natural conditions (Kay et al. 1984, Carlsson-Granér et al. 1998). In our study, by separately examining cases where sexual dimorphism occurs only for flower number or for flower size, and by comparing the visitation patterns in these two situations with trials with no sexual dimorphism, we were able to disentangle the effects flower number vs. flower size sexual dimorphism.

Two important features of our experimental design should be kept in mind when interpreting the results. First, although S. dioica is known to display a generalist insect-pollination system (Baker 1947, Kay et al. 1984), only one pollinator species was used in the experiment. Bombus terrestris was selected because the existing literature describes this species as a common visitor of $S$. dioica (Kay et al. 1984), but different pollinator taxa can display different preferences in terms of floral signals (e.g. Glaettli and Barrett 2008, Gómez et al. 2008), which could in turn impact their response to the level of sexual dimorphism. Second, because the experiments were conducted in a flight arena with fixed numbers of pollinators and visits per pollinator, we could not capture the effects of sexual dimorphism on the overall number of visits at the plant patch level. This overall number of visits should indeed depend both on the number of pollinators visiting the patch (which can increase if males are more attractive, as found by Glaettli and Barrett 2008) and on the length of visitation sequences. Keeping this in mind, we were able to detect interesting effects of sexual dimorphism on pollinator behaviour. 
Experimentally cancelling sexual dimorphism for flower number and size allowed uncovering an innate

271

272

273

274

275

276

277

278

279

280

281

282

283

\section{preference for female flowers}

In the "no dimorphism" treatment, we observed an innate preference of bumblebees for female flowers, both when considering visits at the plant and at the flower level. Pollinators preference for female flowers in gender dimorphic species is rare although it has been observed in a few cases (e.g. gynodioecious Fuschia thymifolia, Cervantes et al. 2018; dioecious Catasetum arietinum: Brandt et al. 2020). The preference towards S. dioica females might be driven by differences in traits that were not measured in the current study, such as nectar production or scent emission. In this species, female flowers produce more abundant but less concentrated nectar than males (Kay et al. 1984). The quantity of sugar per flower was measured in plants from the same collection we used in this experiment in another study (Barbot et al. submitted) and it was observed that, at the flower level, reward is higher in females than in males, which might drive the preference for female flowers. Regarding olfactory signals, while scent emission and composition have been characterized in S. dioica (Jürgens 2004, Page et al. 2014), between sex variation remains unknown to date. In the sister species $S$. latifolia, male flowers release larger amounts of scent than female flowers, with a marked dimorphism for pollinator-attracting compounds (Waelti et al. 2009), a pattern that is common in dioecious insect-pollinated plants (Ashman 2009). Further studies will be needed to determine whether or not scent is sexually dimorphic and whether this trait plays a role in pollinator attraction in S. dioica.

The preference for females in the "no dimorphism" treatment resulted in a higher number of sequences starting by visits on one or several female flowers. This was mainly due to a probabilistic effect: with more female flowers in the sequence, the probability of starting by a female flower increases. In addition, we found that some sequences featured less females visited after a male than expected under random behaviour, which could be driven by a slight active preference for female flowers. As a result, for $38 \%$ of visited female flowers in the «no dimorphism » treatment, the pollination sequence did not feature an upstream visit to a male flower, highlighting the fact that a higher attractivity of females might negatively impact pollination efficiency. 


\section{Flower size dimorphism had no effect on pollinator visitation patterns}

Flower size has been shown to play a role in pollinator attraction in many other systems (e.g. Bell 1985, Galen and Newport 1987, Stanton and Preston 1988). This trait can indeed directly impact the intensity of the visual signal and/or the quantity of reward for pollinators in systems where flower size is associated with reward abundance (Blarer et al. 2002, Brunet et al. 2015). Since no significant preference for males was found when they carried larger flowers, the effect of this trait on pollinator attraction was not supported in our study. One possible explanation is that, if sugar quantity was on average higher in female flowers as expected based on other studies (Barbot et al. submitted), this may have prevented the emergence of a clear preference for large flower sizes. Indeed, we observed a tendency for sexual dimorphism in flower size to offset the innate preference of pollinators for females, but this effect was not significant.

Another study on the same collection of plants showed positive directional selection acting on flower size in males in open pollination conditions (i.e. siring success increased with flower size), although selection intensity appeared weak compared to other traits (Barbot et al. submitted). The apparent discrepancy between our results and the positive selection gradient on flower size detected in males might originate from the fact that our experimental design relied on a minimization of within-sex phenotypic variance in each treatment, implying that the showiest male phenotypes were excluded here.

Flower number dimorphism affected pollinator preference and some features of the pollination sequences, but not pollen transfer

Flower number sexual dimorphism is probably the most notable dimorphism in $S$. dioica. Its magnitude strongly varies across the flowering season, but it is always male biased with a floral sexratio that can reach 1:30 at the end of the flowering season (Moquet et al. 2020). In our experiment, males carried on average four times more flowers than females, which is a relatively low bias in floral sex-ratio compared to what pollinators might encounter in natural populations. In our study, flower number dimorphism cancelled the innate preference of pollinators for females and affected several metrics of bumblebee visitation sequence. 

between the number of flowers and the number of visits (Klinkhamer and de Jong 1990), as found in Jong and Peter 1994). The fact that flower number did not impact siring success in S. dioica (Barbot et necessarily translate into a higher siring success (de Jong and Peter 1994). of female flowers available in each session, we did not record any effects of sexual dimorphism. These results suggest that the observed pattern is not due to any avoidance of female flowers by bumblebees or active preference for male flowers, but mainly to a decrease in the probability of encountering a female flower in the arena when the number of male flower increases. suggest that flower number sexual dimorphism can have conflicting effects on pollination efficiency. Because pollinators visited male flowers more often when male plants had more flowers than females and started their sequence by a male flower much more frequently, the proportion of visited female flowers potentially receiving pollen (i.e. visited after one or several male flowers) was higher with sexual dimorphism. However, because the overall number of visited female flowers was much lower, we found the absolute number of potentially pollinated females to be negatively impacted by sexual dimorphism. 
This result is consistent with the theoretical predictions made by Vamosi and Otto (2002), who argued that decreasing the relative attractivity of female plants should diminish the number of pollinating visits.

One other effect of this higher number of visited male flowers could be that pollinators accumulate a of both pollen grains and insect morphology and behaviour, which was not be measured during the current study. Pollen carryover is generally considered to be high in flowering plants (Robertson 1992). This could explain why no difference was found in the average number of pollen grains deposited on stigmas among treatments. We can suggest that, while the number of potentially pollinating visits decreased with sexual dimorphism, each visit might have been more efficient in terms of pollen deposit. Such quantitative effect was not considered by the model of Vamosi and Otto (2002), which assumed a direct link between the number of pollinating visits and population viability. Other studies found no clear parallel between the number of pollinators visits and pollen receipt of stigmas. For example, in monoecious Sagittaria trifolia, Huang et al. (2006) showed that female flower attractivity to pollinators depended on floral display size and was lower than male plants, but with no clear effect on pollen receipt. The authors explained this result by stigmas being saturated with pollen even after a limited number of pollinators visits. This was not the case in the current study, as evidenced by the high number of stigmas having no or only few pollen grains. In our case, the number of male flowers visited by insects before reaching a female flower was probably critical to explain the variance in the number of pollen grains deposited on stigmas, and may explain the absence of difference between treatments.

To our knowledge, this is the first study to manipulate the occurrence of sexual dimorphism in floral traits and to study its influence on both insect behaviour and pollen transfer. Our results show that analyses of visit sequences and pollen transfer are necessary to understand the possible consequences of sexual dimorphism on pollination success. A higher number of visits on the most attractive sex did not automatically reduce pollen transfer, highlighting the fact that modelling or measuring pollinators visits may not be sufficient to predict the effect on plant reproduction. 
bioRxiv preprint doi: https://doi.org/10.1101/2021.04 15.440026; this version posted April 15, 2021. The copyright holder for this preprint

(which was not certified by peer review) is the author/funder, who has granted bioRxiv a license to display the preprint in perpetuity. It is made available under aCC-BY 4.0 International license.

\section{Acknowledgments}

376 We are grateful to Eric Schmitt and Fanny Raux for their help in collecting the data, as well as to the

377 "Plateforme serre, cultures et terrains expérimentaux - Université de Lille" for the support in plant

378 collection maintenance. This work is a contribution to the CPER research project CLIMIBIO that funded

379 L.M.'s salary. The authors thank the French Ministère de l'Enseignement Supérieur et de la Recherche,

380 the Hauts de France Region and the European Funds for Regional Economical Development for their

381 financial support to this project. 


\section{References}

383

Ågren, Elmqvist, and Tunlid. 1986. Pollination by deceit, floral sex ratios and seed set in dioecious Rubus chamaemorus L. Oecologia 70:332-338.

Ashman. 2009. Sniffing out patterns of sexual dimorphism in floral scent. Functional Ecology 23:852862.

Ashworth and Galetto. 2002. Differential nectar production between male and female flowers in a wild cucurbit: Cucurbita maxima ssp. andreana (Cucurbitaceae). Canadian Journal of Botany 80:1203-1208.

Baker. 1947. Melandrium. Journal of Ecology 35:271-274.

Barbot, Dufaÿ, and De Cauwer. submitted. Natural and sexual selection in an insect-pollinated plant.

Barp, Soares, Giani, Rodrigues, and Moreira. 2011. Variation in nectar and pollen availability, sucrose preference, and daily response in the use of flowers by Heliconius erato phyllis. Journal of Insect Behavior 24:200-219.

Barrett and Hough. 2013. Sexual dimorphism in flowering plants. Journal of Experimental Botany 64:67-82.

Bateman. 1948. Intra-sexual selection in Drosophila. Heredity 2:349-368.

Bell. 1985. On the function of flowers. Proceedings of the Royal Society B: Biological Sciences 224:223-265.

Blarer, Keasar, and Shmida. 2002. Possible mechanisms for the formation of flower size preferences by foraging bumblebees. Ethology 108:341-351.

Bond and Maze. 1999. Survival costs and reproductive benefits of floral display in a sexually dimorphic dioecious shrub, Leucadendron xanthoconus. Evolutionary Ecology 13:1-18.

Brandt, Machado, Navarro, Dötterl, Ayasse, and Milet-Pinheiro. 2020. Sexual dimorphism in floral scents of the neotropical orchid Catasetum arietinum and its possible ecological and evolutionary significance. AoB PLANTS 12. 
bioRxiv preprint doi: https://doi org/10.1101/2021.04 15.440026; this version posted April 15, 2021. The copyright holder for this preprint (which was not certified by peer review) is the author/funder, who has granted bioRxiv a license to display the preprint in perpetuity. It is made available under aCC-BY 4.0 International license.

Brunet, Thairu, Henss, Link, Kluever, and Diggle. 2015. The effects of flower, floral display, and reward sizes on bumblebee foraging behavior when pollen is the reward and plants are dichogamous. International Journal of Plant Sciences 176:811-819.

Campbell. 1989. Inflorescence size: test of the male function hypothesis. American Journal of Botany 76:730-738.

Carlsson-Granér, Elmqvist, Agren, Gardfjell, and Ingvarsson. 1998. Floral sex ratios, disease and seed set in dioecious Silene dioica. Journal of Ecology 86:79-91.

Caruso, Eisen, Martin, and Sletvold. 2019. A meta-analysis of the agents of selection on floral traits. Evolution 73:4-14.

Cervantes, Alvarez, and Cuevas. 2018. Small but attractive: female-biased nectar production and floral visitors in a dimorphic shrub. Plant Biology 20:160-164.

Comba, Corbet, Hunt, and Warren. 1999. Flowers, nectar and insect visits: evaluating British plant species for pollinator-friendly gardens. Annals of Botany 83:369-383.

Conner and Rush. 1996. Effects of flower size and number on pollinator visitation to wild radish, Raphanus raphanistrum. Oecologia 105:509-516.

Costich and Meagher. 2001. Impacts of floral gender and whole-plant gender on floral evolution in Ecballium elaterium (Cucurbitaceae). Biological Journal of the Linnean Society 74:475-487.

Cuevas, Pérez, and Sevillano. 2017. Population size, sex-ratio and sexual dimorphism in Fuchsia parviflora (Onagraceae) an endemic dioecious shrub. Botanical Sciences 95:401-408.

de Jong and Peter. 1994. Plant size and reproductive success through female and male function. Journal of Ecology 82:399-402.

Delph and Ashman. 2006. Trait selection in flowering plants: how does sexual selection contribute? Integrative and Comparative Biology 46:465-472.

Delph, Galloway, and Stanton. 1996. Sexual dimorphism in flower size. American Naturalist 148:299320. 
Eckhart. 1999. Sexual dimorphism in flowers and inflorescences. Pages 123-148 in M. A. Geber, T. E. Dawson, and L. F. Delph, editors. Gender and sexual dimorphism in flowering plants. SpringerVerlag, Berlin.

Galen and Newport. 1987. Bumble bee behavior and selection on flower size in the sky pilot, Polemonium viscosum. Oecologia 74:20-23.

Glaettli and Barrett. 2008. Pollinator responses to variation in floral display and flower size in dioecious Sagittaria latifolia (Alismataceae). New Phytologist 179:1193-1201.

Gómez, Bosch, Perfectti, Fernández, Abdelaziz, and Camacho. 2008. Spatial variation in selection on corolla shape in a generalist plant is promoted by the preference patterns of its local pollinators. Proceedings of the Royal Society B: Biological Sciences 275:2241-2249.

Goulson and Jerrim. 1997. Maintenance of the species boundary between Silene dioica and S. latifolia (red and white campion). Oikos 79:115-126.

Guitián. 1995. Sex ratio, reproductive investment and flowering phenology in dioecious Rhamnus alaternus (Rhamnaceae). Nordic Journal of Botany 15:139-143.

Hegland and Totland. 2005. Relationships between species' floral traits and pollinator visitation in a temperate grassland. Oecologia 145:586-594.

Huang, Tang, Sun, and Lu. 2006. Pollinator response to female and male floral display in a monoecious species and its implications for the evolution of floral dimorphism. New Phytologist 171:417424.

Ishii. 2006. Floral display size influences subsequent plant choice by bumble bees. Functional Ecology 20:233-238.

Jürgens. 2004. Flower scent composition in diurnal Silene species (Caryophyllaceae): phylogenetic constraints or adaption to flower visitors? Biochemical Systematics \& Ecology 32:841-859.

Kay, Lack, Bamber, and Davies. 1984. Differences between sexes in floral morphology, nectar production and insect visits in a dioecious species, Silene dioica. New Phytologist 98:515-529. 
Klinkhamer and de Jong. 1990. Effects of plant size, plant density and sex differential nectar reward on pollinator visitation in the protandrous Echium vulgare (Boraginaceae). Oikos 57:399-405.

Kriebel. 2014. Sexual dimorphism in the flowers of Aegiphila odontophylla (Lamiaceae). Systematic Botany 39:1204-1207.

Lunau. 2000. The ecology and evolution of visual pollen signals. Plant Systematics and Evolution 222:89-111.

Martin. 2004. Flower size preferences of the honeybee (Apis mellifera) foraging on Mimulus guttatus (Scrophulariaceae). Evolutionary Ecology Research 6:777-782.

Matsuhisa and Ushimaru. 2015. Sexual dimorphism in floral longevity and flowering synchrony in relation to pollination and mating success in three dioecious Ilex species. American Journal of Botany 102:1187-1197.

Moore and Pannell. 2011. Sexual selection in plants. Current Biology 21:R176-R182.

Moquet, Lateur, Jacquemart, De Cauwer, and Dufay. 2020. Temporal dynamics of sexual dimorphism in a dioecious species. Annals of Botany 126:471-480.

Nicholls and Hempel de Ibarra. 2017. Assessment of pollen rewards by foraging bees. Functional Ecology 31:76-87.

Page, Favre, Schiestl, and Karrenberg. 2014. Do flower color and floral scent of silene species affect host preference of Hadena bicruris, a seed-eating pollinator, under field conditions? PLoS ONE 9:e98755.

Pailler, Humeau, Figier, and Thompson. 1998. Reproductive trait variation in the functionally dioecious and morphologically heterostylous island endemic Chassalia corallioides (Rubiaceae). Biological Journal of the Linnean Society 64:297-313.

Pickering. 2001. Size and sex of floral displays affect insect visitation rates in the dioecious Australian alpine herb, Aciphylla glacialis. Nordic Journal of Botany 21:401-409. 
R Development Core Team. 2008. R: A language and environment for statistical computing. R Foundation for Statistical Computing, Austria, Vienna.

Ramsey and Vaughton. 2001. Sex expression and sexual dimorphism in subdioecious Wurmbea dioica (Colchicaceae). International Journal of Plant Sciences 162:589-597.

Real. 1981. Nectar availability and bee-foraging on Ipomoea (Convolvulaceae). Biotropica 13:64-69.

Robertson. 1992. The relationship between floral display size, pollen carryover and geitonogamy in Myosotis colensoi (Kirk) Macbride (Boraginaceae). Biological Journal of the Linnean Society 46:333-349.

Sletvold and Ågren. 2016. Experimental reduction in interaction intensity strongly affects biotic selection. Ecology 97:3091-3098.

Spaethe, Tautz, and Chittka. 2001. Visual constraints in foraging bumblebees: Flower size and color affect search time and flight behavior. Proceedings of the National Academy of Sciences

Stanton and Preston. 1988. Ecological consequences and phenotypic correlates of petal size variation in wild radish, Raphanus sativus (Brassicaceae). American Journal of Botany 75:528-539.

Thomson. 1988. Effects of variation in inflorescence size and floral rewards on the visitation rates of traplining pollinators of Aralia hispida. Evolutionary Ecology 2:65-76.

Tsuji, Kobayashi, Hasegawa, and Yoshimura. 2020. Dimorphic flowers modify the visitation order of pollinators from male to female flowers. Scientific Reports 10:9965.

Vamosi and Otto. 2002. When looks can kill: the evolution of sexually-dimorphic floral display and the extinction of dioecious plants. Proceedings of the Royal Society of London B 269:1187-1194. dioecious perennial herb Wurmbea dioica (Liliaceae). Oecologia 115:93-101. Flora 193:113-131. 
bioRxiv preprint doi: https://doi.org/10.1101/2021.04.15.440026; this version posted April 15, 2021. The copyright holder for this preprint (which was not certified by peer review) is the author/funder, who has granted bioRxiv a license to display the preprint in perpetuity. It is made available under aCC-BY 4.0 International license.

506 Waelti, Page, Widmer, and Schiestl. 2009. How to be an attractive male: floral dimorphism and attractiveness to pollinators in a dioecious plant. BMC Evolutionary Biology 9:190. 

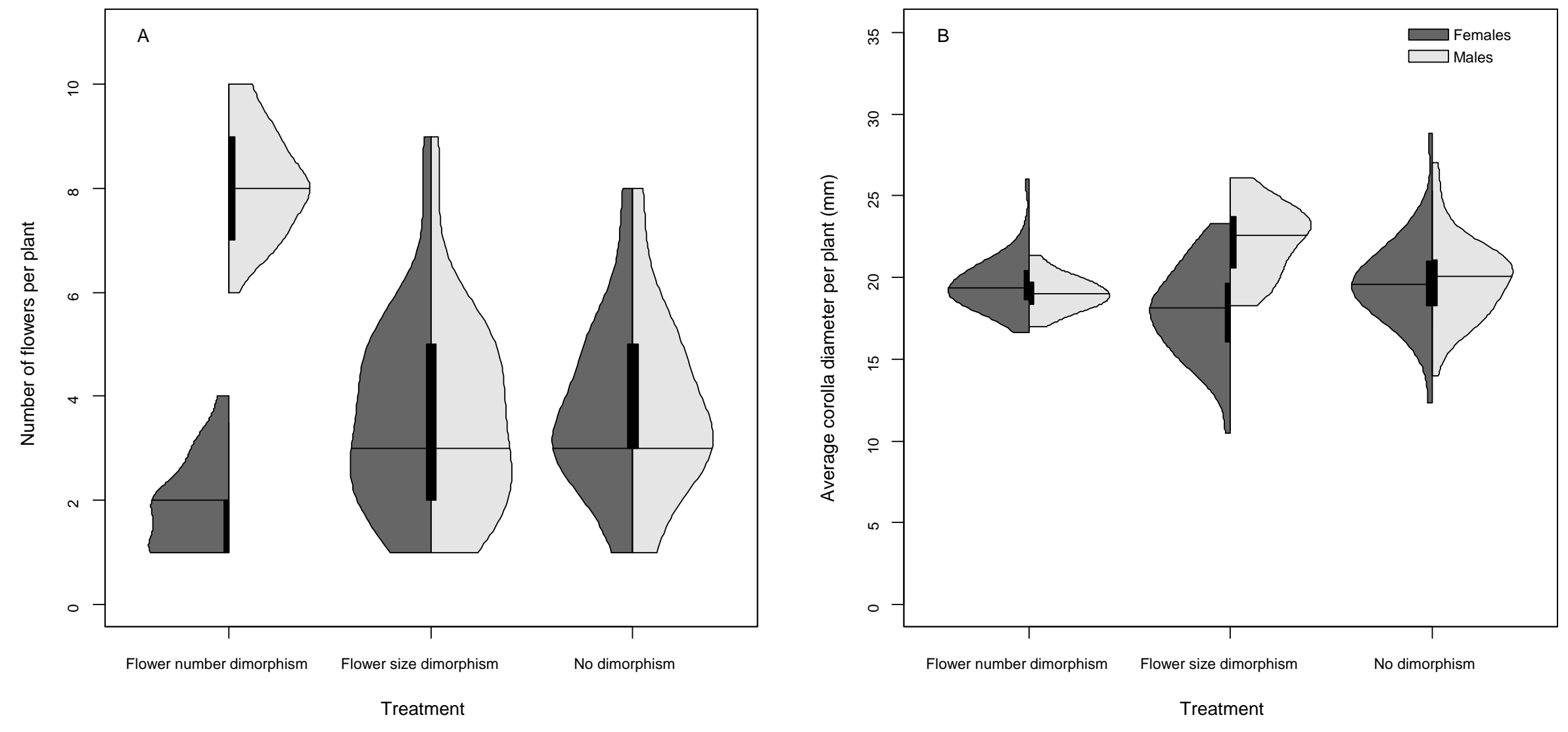
Figure 2 : Number of visits received per plant and per flower, for females (dark grey dots) and for males (light grey triangles). A and B show comparisons between the "no dimorphism" and the "flower number dimorphism" treatment for the number of visits at the plant and flower level respectively. C and D show comparisons between the "no dimorphism" and the "flower size dimorphism" treatment for the number of visits at the plant and flower level respectively.

\section{A}

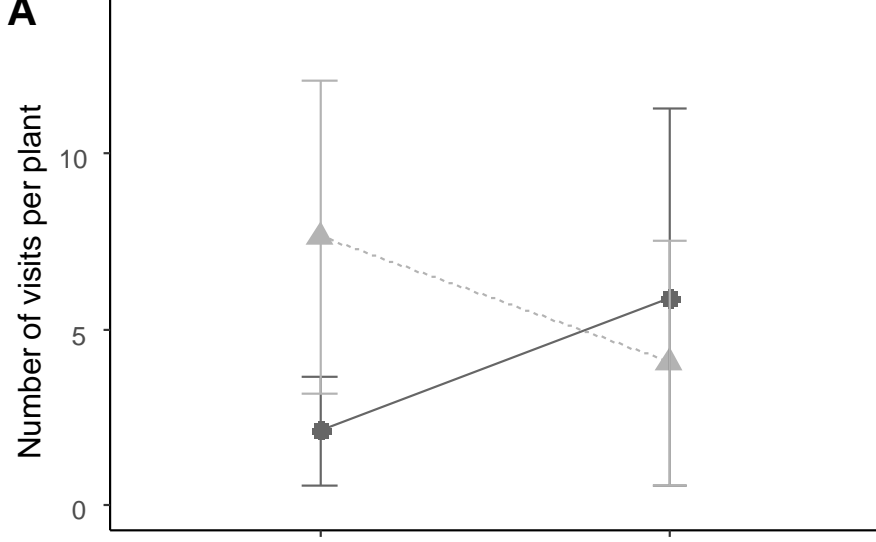

Flower number dimorphism

Treatment

C

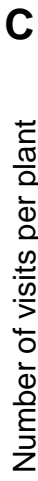

Treatment

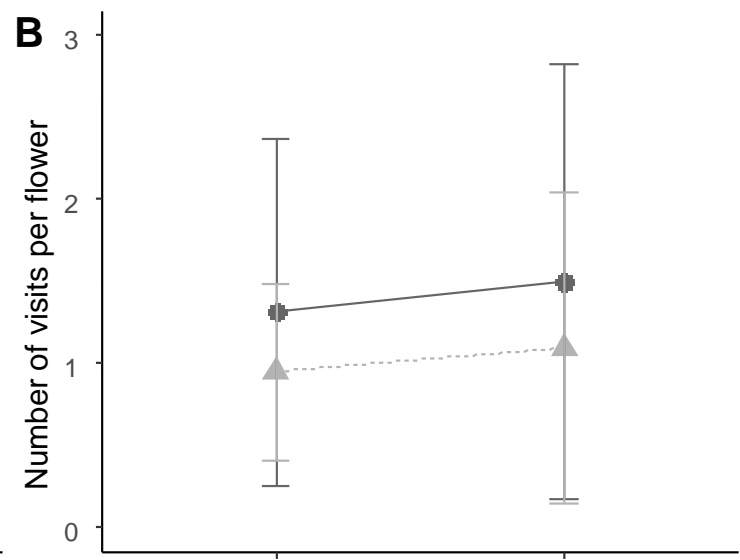

Flower number dimorphism No dimorphism

Treatment

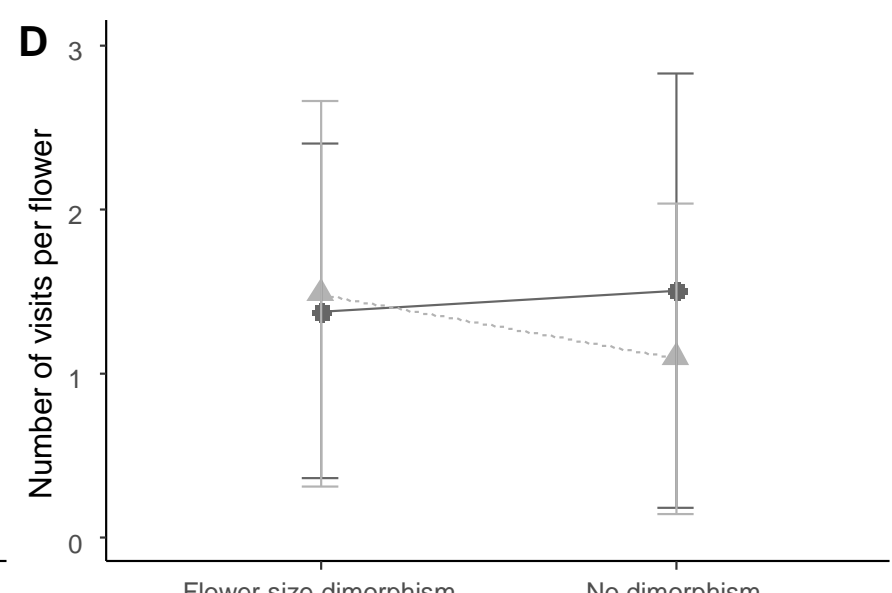

Flower size dimorphism

Treatment 
Figure 3: Violin plots showing the variation in visitation sequences among treatments, with the distribution of: (A) the number of female plants visited per insect (B) : the number of female flowers visited per insect, (C) : the number of visited females flowers divided by the total number of female flowers available in the arena and (D) : the

number of female flowers visited after one or several male flower(s).

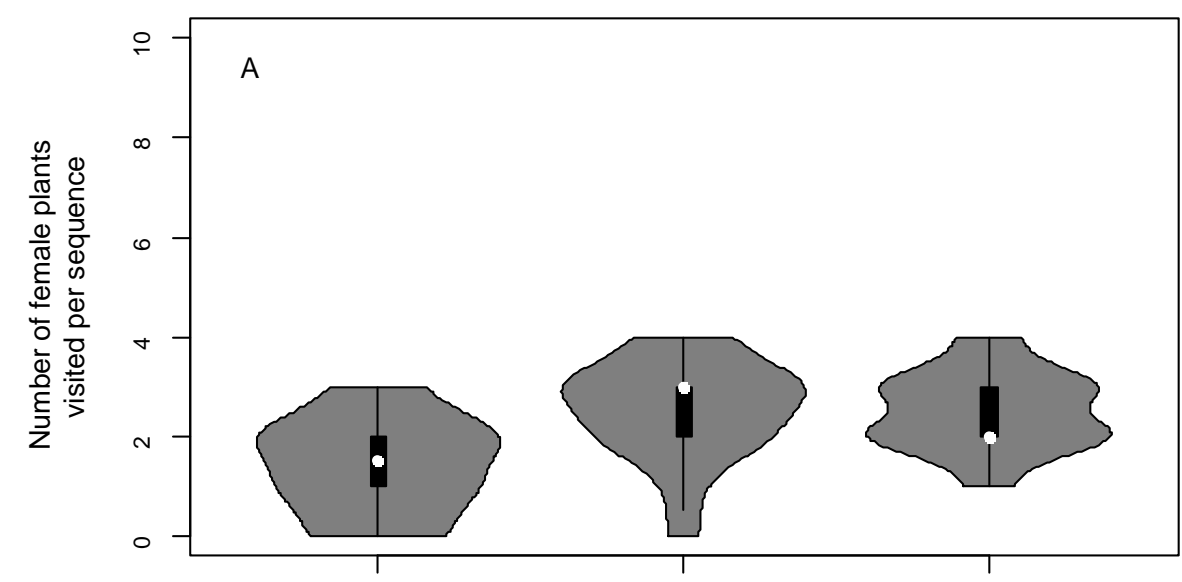

Flower number dimorphism $\quad$ Flower size dimorphism $\quad$ No dimorphism

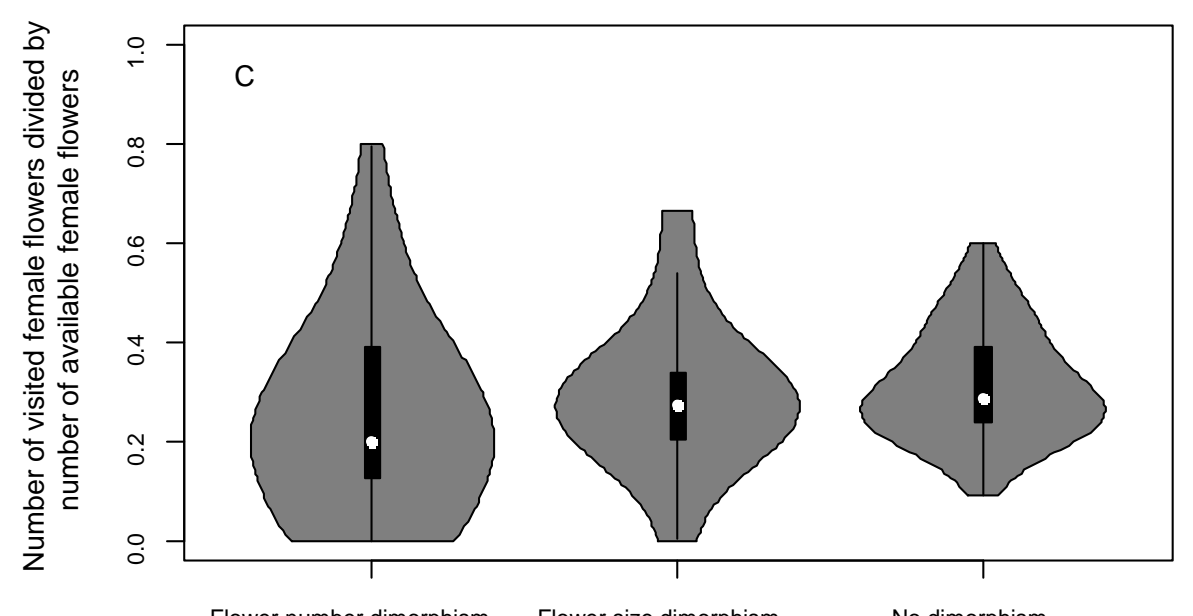

Flower number dimorphism $\quad$ Flower size dimorphism

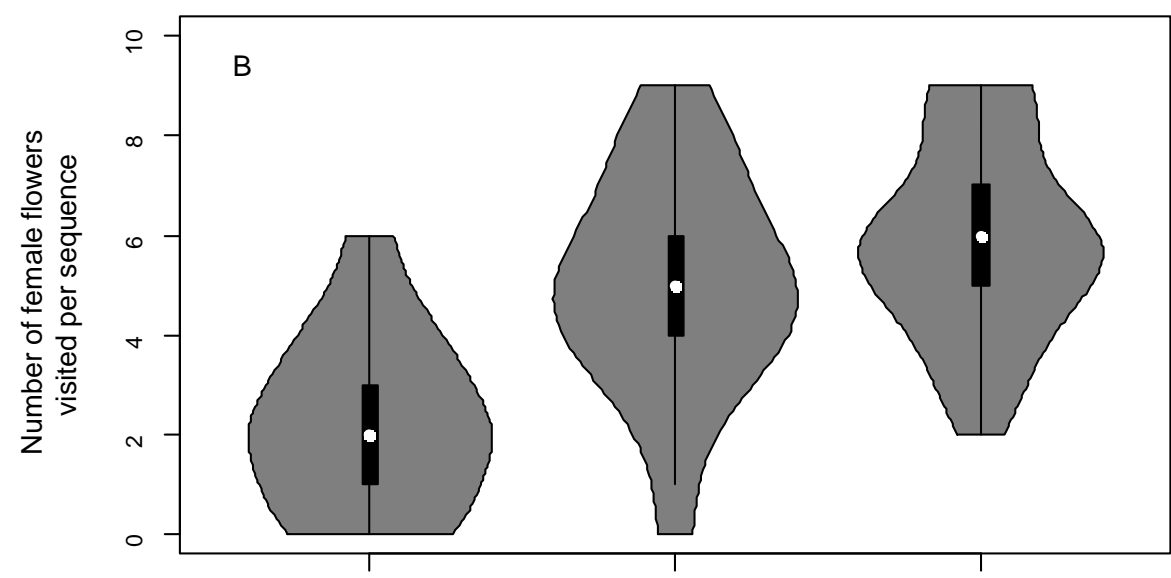

Flower number dimorphism $\quad$ Flower size dimorphism

No dimorphism

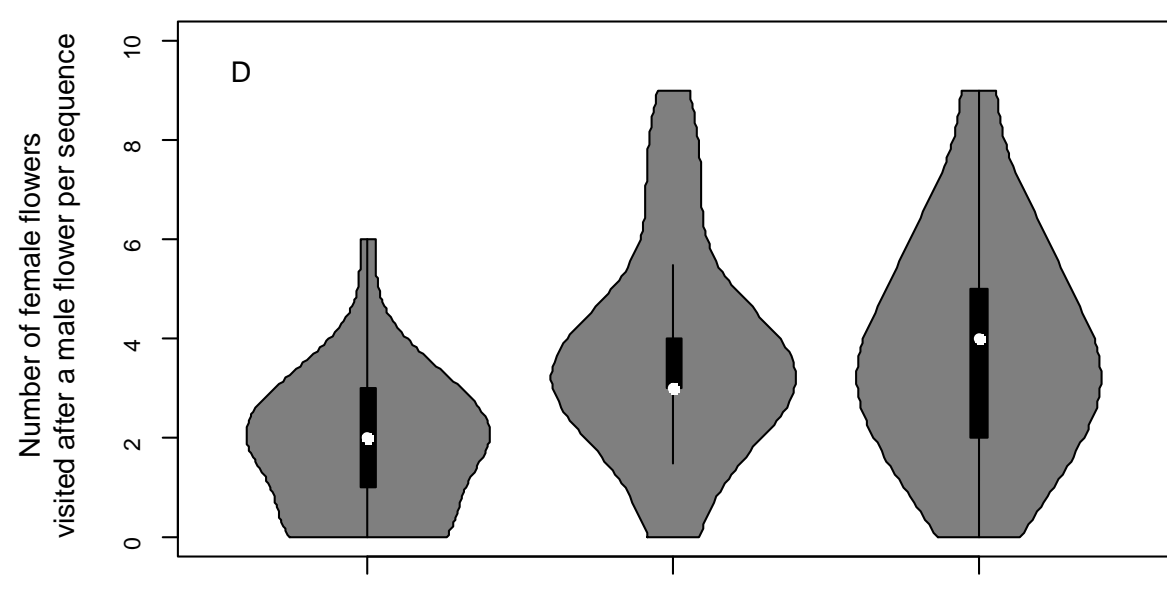

Flower number dimorphism $\quad$ Flower size dimorphism
No dimorphism 
Figure 4: Violin plots showing the distribution of the number of pollen grains per stigma in each treatment. When more than one stigma was collected, pollen counts were averaged across stigmas.

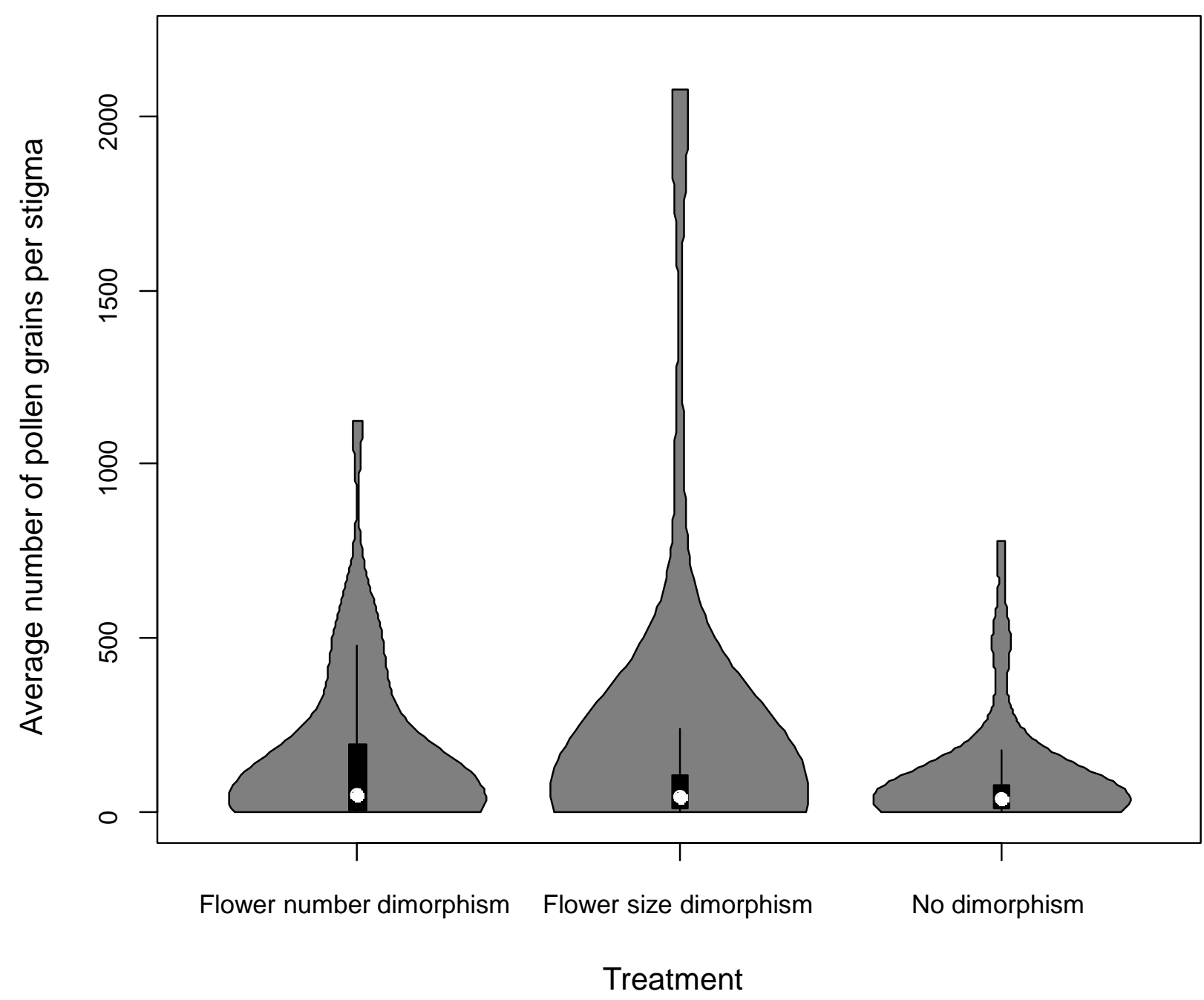


bioRxiv preprint doi: $h t$ tps://doi.org/10.1101/2021.04.15.440026; this version posted April 15, 2021. The copyright holder for this preprint (which was not certified by peer review) is the author/funder, who has granted bioRxiv a license to display the preprint in perpetuity. It is made available under aCC-BY 4.0 International license. 